\title{
Sodium Acetate Anhydrous
}

National Cancer Institute

\section{Source}

National Cancer Institute. Sodium Acetate Anhydrous. NCI Thesaurus. Code C48017.

The anhydrous, sodium salt form of acetic acid. Sodium acetate anhydrous disassociates in water to form sodium ions $(\mathrm{Na}+)$ and acetate ions. Sodium is the principal cation of the extracellular fluid and plays a large part in fluid and electrolyte replacement therapies.

Sodium acetate anhydrous is used as an electrolyte replenisher in isosmotic solution for parenteral replacement of acute losses of extracellular fluid without disturbing normal electrolyte balance. 